\title{
PLM-MES integration to support Industry 4.0
}

\author{
Gianluca D’Antonio ${ }^{1}$, Lisa Macheda ${ }^{2}$, Joel Sauza Bedolla ${ }^{1}$, Paolo Chiabert ${ }^{1}$, \\ ${ }^{1}$ Politecnico di Torino, corso Duca degli Abruzzi 24, 10129, Torino, Italy \\ \{gianluca.dantonio, joel.sauza, paolo.chiabert\}@polito.it \\ ${ }^{2}$ AEC Soluzioni, corso Unione Sovietica 612/3A, 10135, Torino, Italy \\ aec@aecsoluzioni.it
}

\begin{abstract}
In order to effectively deal with the Industry 4.0 paradigm, companies need accurate strategies to manage data collected on both the real world and its virtual counterpart. Proper information systems need to be implemented; Product Lifecycle Management (PLM) and Manufacturing Execution Systems (MES) play a key role in this task. A primary issue is the mutual integration of such systems, with the aim of reducing time and cost for data management, as well as risks of errors and data redundancy. The present paper aims to present the results of a survey submitted to a set of Italian companies to measure their digital maturity and their proneness in implementing further information systems and in enabling their integration.
\end{abstract}

Keywords: Product Lifecycle Management, Manufacturing Execution Systems, Information systems, Industry 4.0.

\section{Introduction}

Today, one of the most popular keywords in the field of manufacturing is "Industry 4.0". Despite a wide variety of scientific, technical and business literature, a shared definition of Industry 4.0 has not yet been achieved. However, the most of authors agree in stating that this paradigm relies on the implementation of the Internet of Things (IoT) technology in manufacturing environment [1]. The wide-scale deployment of IoT will promote enhanced communication between humans and machines and support the implementation of the so-called Cyber-Physical Systems (CPS) [2], i.e. systems consisting in a real entity (for example, a machine) and its corresponding virtual model - embedding all the models for mimicking the behavior of the real counterpart - capable to communicate with each other.

In order to implement a CPS, two complementary and parallel approaches are necessary: (i) cyberizing the physical, and (ii) physicalizing the cyber [3]. To deal with the first task, a virtual model of each entity in the physical factory must be realized. Then, simulation models must be implemented to transform the static models in dynamic systems. An integration between the virtual and the physical worlds is necessary to feed virtual models with data acquired in field, aiming to simulate future scenarios without the need to input data manually [4]. Next, all the communication 
between machine and network, machine-to-machine and machine-to-human should be flawlessly designed.

This approach can be extended from company resources to products: physical products should be transformed in uniquely identifiable information carriers, which may be whenever located to know their history, status and alternative routes to achieve their target state [5].

Hence, machines need to be equipped with enough computing and communication capabilities to have the ability to act independently, without direct human intervention. Further, a structured approach to manage the wide quantity of data that can be collected is necessary and information systems should be properly integrated.

In previous work [6], a roadmap to achieve the smart factory has been depicted. The present paper aims to focus on the role that Product Lifecycle Management (PLM) and Manufacturing Execution Systems (MES) - as well as their integration - can play in supporting the Industry 4.0 paradigm. An analysis of possible benefits is provided; moreover, the results of a survey made to measure the interest of manufacturing companies in this topic are presented.

The remainder of the paper is organized as follows. In Section 2, the state of the art is depicted and the role of PLM-MES integration in supporting the Industry 4.0 paradigm is presented. The structure of the survey is presented in Section 3; the results are provided in Section 4. Conclusive remarks and hints for future work are discussed in Section 5.

\section{Information systems supporting Industry 4.0}

\subsection{Product Lifecycle Management}

Over the last decade PLM has become one of the key technological and organizational approaches and enablers for the effective management of product development and product creation processes [7]. Product information is generated when the product is first conceived, then it continues to evolve with the addition of ComputerAided Design (CAD) models and drawings detailed specifications, user manuals, manufacturing instructions, service manuals, disposal and recycling instructions [8]. The management of the life cycle of products and related services has become a central factor in the manufacturing industry.

Manufacturing is the function that has the greatest benefit from the application of PLM technology [9]. The manufacturing objective is to fabricate a product with precisely defined specifications and tolerances utilizing the least amount of resources. In order to reduce the time to market, manufacturing companies have relied more and more on simulations to early (and digitally) test and optimize the manufacturing process. Simulations are used in both long-term decisions, such as facility layout and system capacity configuration, and short-term decision-making, as for example CNC simulation [10]. The term that resume this concept is Digital Manufacturing (DM). It represents the production data management systems and simulation technologies that are jointly used for optimizing manufacturing before starting the production and supporting the ramp-up phases [11]. DM is considered as one of the main technologies 
to enable the next frontier in manufacturing, the so-called Cyber Physical Production System (CPPS) [12]. CPPS are defined as systems of collaborating computational entities in constant connection with the surrounding physical world with its on-going processes, providing and using (at the same time) data-accessing and data-processing services available on the internet [13]. CPPS are a core element of Industry 4.0; hence, the integration of the DM and the CPPS would be a milestone for this paradigm.

In this background, PLM is the backbone of the digitalization, simulation and integration of systems. CPPS require a digital model of all the equipment in the factory along with the product itself. PLM connects and maintains the integrity of the systems and plays a fundamental role in the management of product and process changes. However, the PLM structure will need to be adapted to the growing amount of information that will received from the shop floor and from the product at use stage.

\subsection{Manufacturing Execution Systems}

Manufacturing Execution Systems are IT tools that enable information exchange between the organizational level of a company - commonly supported by an ERP - and the control systems for the shop-floor, usually consisting in several, different, very customized software applications [14].

A MES has two principal purposes. First, the system has to identify the optimal sequence planning taking into account the constraints of the process, such as the times for processing and setup, and the capacity of the workstations, taking into account the requirements and the necessities given by the organizational level. The system also has to manage and allocate resources such as the staff and the material necessary for the manufacturing process.

The second aim of a MES is to manage the bottom-up data flow. The data collection necessary for feeding the CPS is triggered by the recent development of low-cost, small, easily available sensors. MES is in charge of collecting the data gathered on the shopfloor, analyze it through proper mathematical techniques, and extract the information necessary to provide an exhaustive picture of the current state of the process. Possibly, the analysis should be performed in real-time, in order to make decisions to control the process with the necessary rapidity.

Given this background, MES plays a strategic role in supporting Industry 4.0: it is a platform for transforming data collected on the shop-floor into information, which can feed the simulation models and, in turn, enable DM.

\subsection{Integration between PLM and MES}

Up-to-date, few work in the field of PLM-MES integration has been done. A first attempt has been made by Ben Khedher et al. [15]: they analyze the data exchange between the PLM and MES systems and propose a model for this integration. Nevertheless, this general model lacks of validation, since no evidence of application is shown. This is the only work in which a methodological approach is proposed.

In previous work, D'Antonio et al. [16] identified the benefits resulting from the integration between PLM and MES through a case-study in the manufacturing of 
aeronautics components. In [17], a case-study in the field of automotive has been analyzed. In both the two works, the main benefit deriving from the integration between the two systems could be the reduction of errors in information management and the improved reactivity in taking decisions.

The integration between PLM and MES would allow to realize a synchronized system where product design and production are strictly tied. In the flow from design to production, the PLM contains the information necessary to define the properties of the finite part to be manufactured. The MES contains the information necessary to transform the product defined in the PLM into a physical object, such as the routings and the process parameters. The PLM also contains data concerning the features necessary to ensure a proper product quality, while the MES contains the operative steps required to evaluate product quality. In summary, MES should only contain process information, while product information should be stored in the PLM; however, in many cases, MES also contain product information. This may lead to duplicate information (i.e. information contained both in the PLM and in the MES), with possible risks for errors.

In the opposite flow (i.e. from production to design), MES is the repository of the in-field information collected on the shop-floor. This role is enhanced by the Industry 4.0 paradigm: resources will be increasingly equipped with sensors and devices for data acquisition, and a structured approach for their analysis and collection is necessary. A connection between PLM and MES enables product managers and designers to identify at any time possible criticalities, evaluate their impact and develop possible solutions. This can lead to an overall product quality improvement: as soon as a criticality is found, designers can take decisions to solve it, based on the data collected on the shopfloor and stored in the MES. Further, when a new product is released, the ramp-up production phase can be tightly monitored through the MES, and the necessary adjustments to product features or to the control plans can be quickly done.

\section{Structure of the survey}

The survey used to measure the proneness of manufacturing companies in integrating information systems has been implemented through the free tool made available by Google. The structure of the survey is made of five steps.

Step 1. Introduction. The name of the company in which the recipient is employed is required, and a short description about the aim of the survey is provided. However, to guarantee anonymity, the reply to this question was not mandatory.

Step 2. Digital maturity. The recipient is asked to select from a given list the information systems that are currently used in his company. The possible answers are: CAD; PDM; ERP; PLM; MES; SCM; Other. In a further question, the recipient is asked whether any of these information systems are mutually integrated, with particular concern for: ERP-MES; CAD-PLM; ERP-PLM; SCM-MES.

Step 3. Focus on PLM. Here, a short definition of PLM and its aims is provided; then, the recipient is asked whether he is interested in integrating a PLM system in his company, and which are the expected benefits, among: (i) Time and cost reduction for product development; (ii) Improvement in product information management and 
sharing; (iii) Improved traceability of new product releases; (iv) Overall product quality improvement, due to updated and shared product specifications; (v) Improved product management due to detailed BOM. In case the company is already equipped with a PLM system, the name of the deployed software is requested.

Step 4. Focus on MES. The structure of this section is similar to the previous one. A short definition of MES and its role is provided. Then, the recipient is asked whether his company is interested in using a MES and which would be the expected benefits, among: (i) Improved process management and monitoring; (ii) Improved cost management and monitoring; (iii) Acquisition of data collected on-field from the machines; (iv) Improved management of criticalities, such as non-conformities, breaks, failures; (v) Integrated management of the flow of materials and information flowing through the process; (vi) Improved production planning. In case the company is already equipped with a MES, the name of the deployed software is requested.

Step 5. Focus on PLM-MES integration. A set of possible advantages resulting from the integration between PLM and MES is provided. Then, the recipient is asked whether his company could be interested in a possible integration the PLM system with a MES and which would be the expected benefits, among: (i) Time-to-market reduction; (ii) Integration between design and production activities; (iii) Improvement in information traceability; (iv) Improvement of the quality level provided to the customer.

\section{Results}

The invitation to submit the survey described in Section 3 has been sent to 400 companies settled in the Piemonte region (Italy). Small, Medium and Large companies involved in different manufacturing areas have been contacted; a detailed description of the sample is provided in Table 1.33 replies were obtained, corresponding to the $8 \%$ of the initial sample; although a low value, it is in line with the results commonly obtained by surveys. Among the respondents, 21 people also stated the name of the company for which they are employed. In the following, the results for each survey section are shown; a graphical representation is provided in Figure 1

Digital maturity. The companies that state to deploy CAD software are 30; the only companies that do not deploy such tool are involved in Food \& Beverage and in Logistics. The second most popular information tool is the ERP: this kind of software is used in 21 companies among the ones that replied to the survey, while 9 companies deploy a PDM tool. SCM is used by three companies. MES is used by 8 companies; among them, 7 state that the software is directly integrated with an ERP, and in three cases the integration with a SCM has also been implemented. PLM is used in 6 companies. Among them, in three cases PLM is integrated with the ERP and in two cases it is also integrated with the CAD software; conversely, in the other three cases, there is no integration between PLM and other information systems. No companies own both a PLM and a MES.

Focus on PLM. As said, among the 33 companies that replied to the survey, 6 ones already have a PLM system. 15 companies state to be not interested in implementing such solution, while 12 companies are interested. All of them would appreciate a solution enabling to improve management and sharing of product information; 9 of 
them are interested in improving the traceability of product changes, while 7 companies aim to reduce time and cost for new product development.

Table 1. Synthesis of the companies involved in the survey, organized by manufacturing field and by company size.

\begin{tabular}{|c|c|c|}
\hline Manufacturing field & Invited companies & Submitted surveys \\
\hline Mechanics & 205 & 9 \\
\hline Automotive & 51 & 2 \\
\hline Textile & 39 & 3 \\
\hline Food \& Beverage & 30 & --- \\
\hline Building components & 21 & 1 \\
\hline Chemistry & 14 & --- \\
\hline Electronics & 12 & --- \\
\hline Aerospace & 7 & --- \\
\hline Glass/Wood & 6 & 3 \\
\hline Logistics & 6 & 12 \\
\hline Consumer products & 9 & 33 \\
\hline Unknown & --- & 3 \\
\hline Total & 400 & 12 \\
\hline \hline Company size & Invited companies & Submitted surveys \\
\hline $\begin{array}{c}\text { Small companies } \\
\text { (10-50 employees) }\end{array}$ & 18 & 6 \\
\hline $\begin{array}{c}\text { Medium companies } \\
\text { (50-250 employees) }\end{array}$ & 294 & 12 \\
\hline $\begin{array}{c}\text { Large companies } \\
\text { (250+ employees) }\end{array}$ & 88 & 33 \\
\hline Unknown & --- & \\
\hline Total & 400 & \\
\hline
\end{tabular}

Finally, 4 companies would adopt a PLM system to have an overall product quality improvement, and three companies aim to be supported in having complete and exhaustive BOMs and thus improve the management of new product configurations.

Focus on MES. Eight companies that replied to the survey already use a MES. Among the other ones, 9 would be interested in a MES, while 16 are not. The most popular advantages expected from the deployment of a MES are: the improved cost management and monitoring (8 preferences), the improved process management and monitoring, and the integrated management of the flow of materials and information flowing through the process ( 7 preferences each). The capability to acquire process data in real-time from the shop-floor and an improved management of failures and nonconformities are also appreciated (5 preferences each).

Focus on PLM-MES integration. According to the results obtained in the second section, none of the companies that replied to the survey own both a PLM and a MES. In this section, an overview of the possible benefits coming from such integration was provided. After reading this list, 16 companies stated that such advantages could be interesting, while 17 declared to be not interested in a PLM-MES integration. 

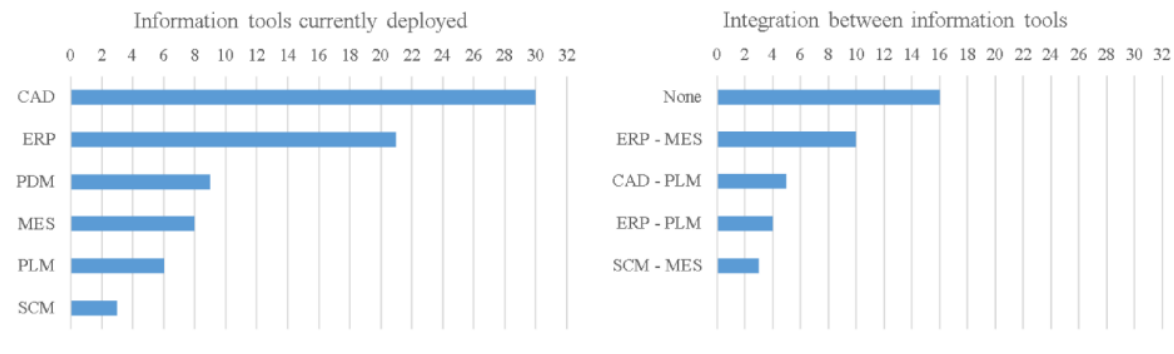

Interest in PLM

Expected benefits

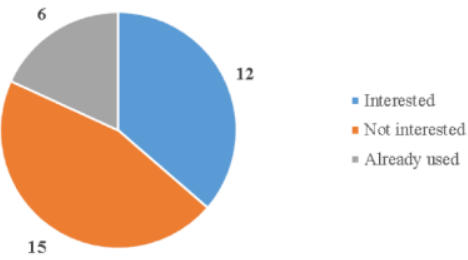

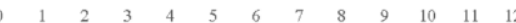
Improvement in product information management and sharing

\begin{tabular}{|l|}
\hline Improved traceability of new product releases \\
\hline Time and cost reduction for product development \\
\hline Improved product management due to detailed BOM \\
\hline Overall product quality improvement \\
\hline
\end{tabular}

Interest in MES

Expected benefits

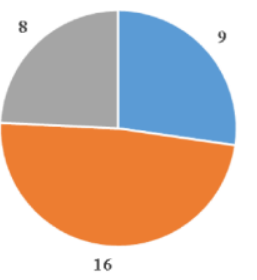

- Interested

- Not interested

- Already used

Interest in PLM-MES integration

Expected benefits

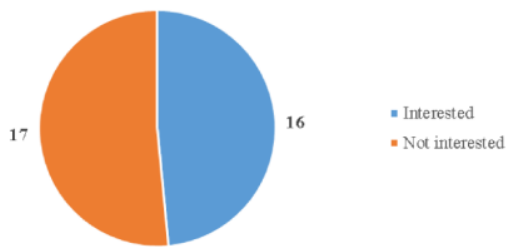

$\begin{array}{llllll}0 & 1 & 2 & 3 & 4 & 5\end{array}$

Improved cost management and monitoring

Improved process management and monitoring

Integrated management of the flow of materials and information

Improved production planning

Acquisition of data collected on-field from the machines

Improved management of criticalities

$\begin{array}{lllllllllllllllll}0 & 1 & 2 & 3 & 4 & 5 & 6 & 7 & 8 & 9 & 10 & 11 & 12 & 13 & 14 & 15 & 16\end{array}$ Improvement of the quality level provided to the customer

Integration between design and production activities

Time-to-market reduction

Thedention

Improvement in information traceability

Figure 1. Results of the survey. 


\section{Conclusions}

The aim of this paper was to measure the interest of manufacturing companies in deploying information systems to enhance their activities. The attention was focused on PLM, MES and their integration; in particular, the latter system plays a key role in managing the huge amount of data that can be collected through the information technologies triggering the Industry 4.0 paradigm.

Two main results are highlighted by the present work. First, the interest of companies in the benefits provided by the systems taken into account is high; in particular, the highest interest rate (approximately 50\%) is obtained by the advantages of integrating the two systems. Nonetheless, none of the interested companies already own both the two systems. Hence, although the interest rate is high, the current industry is not yet ready for PLM-MES integration. The second result is that, although this interest, a standard methodology for PLM-MES integration does not exist yet. Therefore, further work must be done in this direction.

\section{References}

[1] Industrie 4.0 Working Group, "Recommendations for implementing the strategic initiative Industrie 4.0," 2013.

[2] M. Brettel, N. Friederichsen, M. Keller and M. Rosenberg, "How virtualization, decentralization and network building change the manufacturing landscape: An Industry 4.0 perspective," International Journal of Mechanical, Aerospace, Industrial, Mechatronic and Manufacturing Engineering, vol. 8, pp. 37-44, 2014.

[3] R. Anderl, "Industrie 4.0 - Advanced engineering of smart products and smart production," in The 19th International Seminar on High Technology, Piracicaba, Brasil, 2014.

[4] E. Westkämper and L. Jendoubi, "Smart Factories - Manufacturing environments and systems of the future," in The 36th CIRP-International Seminar on Manufacturing Systems, Saarbruecken, Germany, 2003.

[5] D. Gorecky, M. Schmitt, M. Loskyll and D. Zühlke, "Human-Machine-Interaction in the Industry 4.0 Era," in The 12th IEEE International Conference on Industrial Informatics (INDIN), Porto Alegre, 2014.

[6] J. Sauza Bedolla, J. Mora Orozco, Á. d. J. Guarín Grisales, G. D'Antonio and P. Chiabert, "PLM in a didactic environment: the path to smart factory," International Journal of Product Lifecycle Management, vol. 9, no. 4, pp. 333-352, 2016.

[7] M. Abramovici, "Future Trends in Product Lifecycle Management," in The future of product development, Springer, 2007, pp. pp 665-674.

[8] K. Framling, S. Kubler and A. Buda, "Universal messaging standards for the IoT from a Lifecycle Management perspective," IEEE Internet of Things Journal, pp. 319-327, 2014.

[9] M. Grieves, Product Lifecycle Management: Driving the Next Generation of Lean Thinking, McGraw Hill Professional, 2005.

[10] D. Mourtzis, N. Papakostas, D. Mavrikios, S. Makris and K. Alexopoulos, "The role of simulation in digital manufacturing: applications and outlook," International Journal of Computer Integrated Manufacturing, pp. 3-24, 2015. 
[11] E. Westkämper, "Strategic Development of Factories under the Influence of Emergent Technologies," CIRP Annals - Manufacturing Technology, p. Pages 419-422, 2007.

[12] K. Jackson, K. Efthymiou and J. Borton, "Digital Manufacturing and Flexible Assembly Technologies for Reconfigurable Aerospace Production Systems," in The Sixth International Conference on Changeable, Agile, Reconfigurable and Virtual Production (CARV2016), 2016.

[13] L. Monostori, "Cyber-physical production systems: Roots, expectations and R\&D challenges," in Proceedings of the 47th CIRP Conference on Manufacturing, 2014.

[14] H. Meyer, F. Fuchs and K. Thiesl, Manufacturing Execution Systems (MES): Optimal design, planning, and deployment, McGraw-Hill Professional, 2009.

[15] A. Ben Khedher, S. Henry and A. Bouras, "Integration between MES and Product Lifecycle Management," in IEEE International Conference on Emerging Technologies and Factory Automation (ETFA '11), Toulouse, 2011.

[16] G. D'Antonio, J. Sauza Bedolla, P. Chiabert and F. Lombardi, "PLM-MES integration to support collaborative design," in International Conference on Engineering Design (ICED15), Milano, Italy, 2015.

[17] G. D’Antonio, J. Sauza Bedolla, G. Genta, S. Ruffa, G. Barbato, P. Chiabert and G. Pasquettaz, "PLM-MES integration: a case-study in automotive manufacturing," in The 12th International Conference on Product Lifecycle Management (PLM15), Doha, Qatar, 2015. 